\title{
Groundwater management based on monitoring of land subsidence and groundwater levels in the Kanto Groundwater Basin, Central Japan
}

\author{
K. Furuno ${ }^{1}$, A. Kagawa ${ }^{2}$, O. Kazaoka ${ }^{2}$, T. Kusuda ${ }^{3}$, and H. Nirei ${ }^{4}$ \\ ${ }^{1}$ IUGS-GEM Japan branch, 6-41-8, Kotehashidai, Hanamigawa-ku, Chiba 262-0005, Japan \\ ${ }^{2}$ Research Institute of Environmental Geology, Chiba, Japan \\ ${ }^{3}$ Chiba Environmental Foundation, Chiba, Japan \\ ${ }^{4}$ The Geo-pollution Control Agency, Chiba, Japan \\ Correspondence to: K. Furuno (kuniofurunojp@gmail.com)
}

Published: 12 November 2015

\begin{abstract}
Over 40 million people live on and exploit the groundwater resources of the Kanto Plain. The Plain encompasses metropolitan Tokyo and much of Chiba Prefecture. Useable groundwater extends to the base of the Kanto Plain, some 2500 to $3000 \mathrm{~m}$ below sea level. Much of the Kanto Plain surface is at sea level. By the early 1970s, with increasing urbanization and industrial expansion, local overdraft of groundwater resources caused major ground subsidence and damage to commercial and residential structures as well as to local and regional infrastructure. Parts of the lowlands around Tokyo subsided to $4.0 \mathrm{~m}$ below sea level; particularly affected were the suburbs of Funabashi and Gyotoku in western Chiba. In the southern Kanto Plain, regulations, mainly by local government and later by regional agencies, led to installation of about 500 monitoring wells and almost 5000 bench marks by the 1990's. Many of them are still working with new monitoring system. Long-term monitoring is important. The monitoring systems are costly, but the resulting data provide continuous measurement of the "health" of the Kanto Groundwater Basin, and thus permit sustainable use of the groundwater resource.
\end{abstract}

\section{Introduction}

The Kanto plain is also called "the Kanto fore-arc submarine basin" or "the paleo-Kanto-submarine basin", based on surrounding geologic and physiographic features such as Nasu Volcanic Zone, Fuji Volcanic Zone, Japan trench and Izu-Ogasawara Trench (Nirei et al., 1990). Over 40 million people live on the Kanto plain which includes the Tokyo metropolis. The waterfront area around Tokyo Bay mostly includes both alluvium and man-made strata such as reclaimed areas and is densely covered with houses and factories. Sediments of the Kanto basin are 2500-3000 m thick and are of Miocene to Holocene age. The basin is also called the Kanto groundwater basin from the standpoint of the production of groundwater, natural gas and iodine which are contained in fossil sea water. Uncontrolled use of groundwater has caused land subsidence. To ensure effective use of groundwater, a monitoring system for their management has been developed. The system has about 500 self-recording observation wells, almost 5000 bench marks (leveled every year). Over-pumping of the groundwater (fresh water and brine groundwater) resulted in a serious land subsidence problem in various areas, especially alluvial plains and reclaimed area so that it was inevitable to control the groundwater use to solve the problem (Aihara et al., 1969). Consequently, systematic observations of pumping up volumes, groundwater level changes and land subsidence records for the effective groundwater use have been carried out for preventing the land subsidence from a geological point of view (Research Committee on Land subsidence Prevention in Southern Kanto District, 1974). 


\section{Kanto groundwater basin and underground fluid resources}

The Kanto Paleo-submarine basin can be called the Kanto groundwater basin from the standpoint of the distribution and the fluidity of the underground fluid resources (Nirei and Furuno, 1986). The bottom of the groundwater basin corresponds to the base of Kanto tectonic basin, which is situated at $3000-2500 \mathrm{~m}$ below the surface. The sediments of the Kazusa sub-groundwater basin in the basin contains brine groundwater (fossil sea water) including natural gas and iodine (Figs. 1,2). The equivalent layer of the Kazusa Group that extended to the western and northern part of the Kanto plain is composed of alternating beds of coarse- to fine-grained deposits is suitable for groundwater. The lower part of the Shimosa sub-groundwater basin contains groundwater colored with humid material from the northern to central part of the Boso peninsula, and the colored groundwater is unsuitable for drinking. In the upper part of the Shimosa sub-groundwater basin, most of the aquifer layers contain fresh water; this basin had the largest pumpage volume of water in the Kanto groundwater basin. However, the more pumping up volume increased, the lower the groundwater level became in the Shimosa upper sub-groundwater basin. Which is also resulted in lowering of groundwater level even in the alluvial deposits as well as subsiding of ground surface. It is now widely confirmed that the amount of ground subsidence is affected by the thickness of alluvial deposits (Research Institute of Environmental Geology, 1979).

\section{Status of underground fluid resource use}

Natural gas and groundwater have been produced as the underground fluid resources in the Kanto groundwater basin. The former is mainly derived from the Kazusa subgroundwater basin. Annual production of natural gas was 520 million $\mathrm{Nm}^{3}$ in 1980,460 million $\mathrm{Nm}^{3}$ in 2003 and 440 million $\mathrm{Nm}^{3}$ in 2011. The natural gas produced from the Kazusa sub-groundwater basin was contained in fossil sea water of the Kazusa group. Accordingly, it was inevitable to pump up the fossil sea water when releasing natural gas, which frequently caused a land subsidence problem. Therefore, the pumping is now limited to the area of hills and the Pacific coast in the southern Kanto, a considerable distance from the metropolitan area. Recently, the groundwater is mainly pumped up at the marginal area of the Shimosa lower sub-groundwater basin and the upper Shimosa sub-groundwater basin. Annual pumped volume was 3.4 million $\mathrm{m}^{3}$ day $^{-1}$ in 1978 and 3.1 million $^{3}$ day $^{-1}$ in 2003 (Prefectural Governors' Committee for Land subsidence Prevention in Kanto District, 1983, 2008) and 2.8 million $\mathrm{m}^{3}$ day $^{-1}$ in 2015 (Ministry of Environment, 2015). These data were obtained in the limited area where reporting of pumped volume is required of groundwater users by regulation for preventing land subsi-

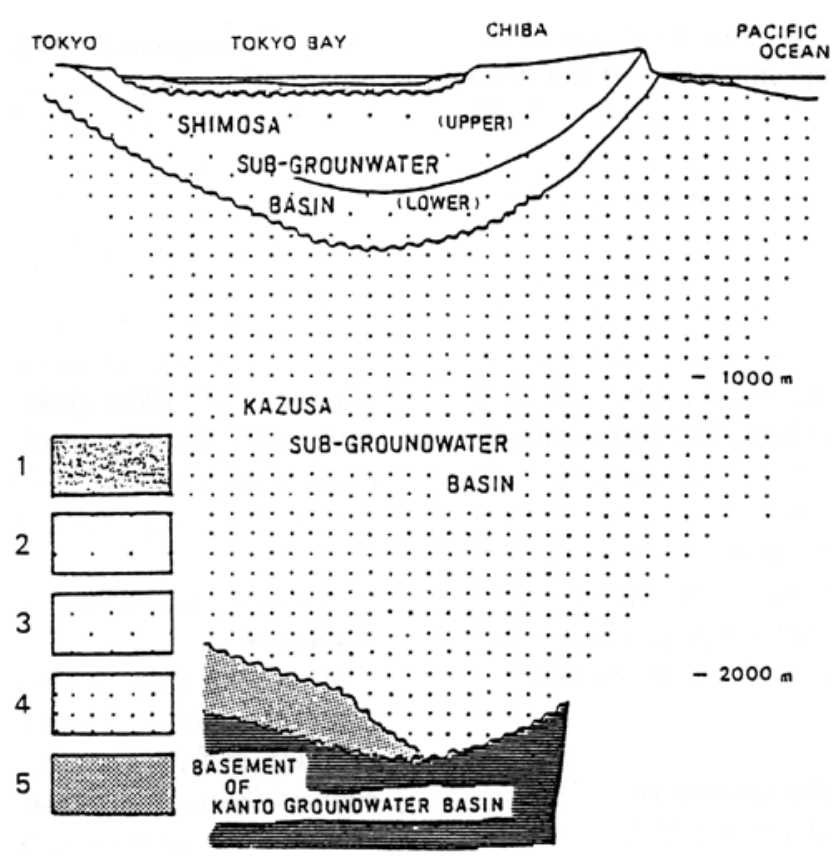

Figure 1. Schematic section of the Kanto groundwater basin: 1: alluvial deposits, 2: upper part of the Shimosa Group, 3: lower part of the Shimosa Group, 4: Kazusa Group, 5: Miura Group.

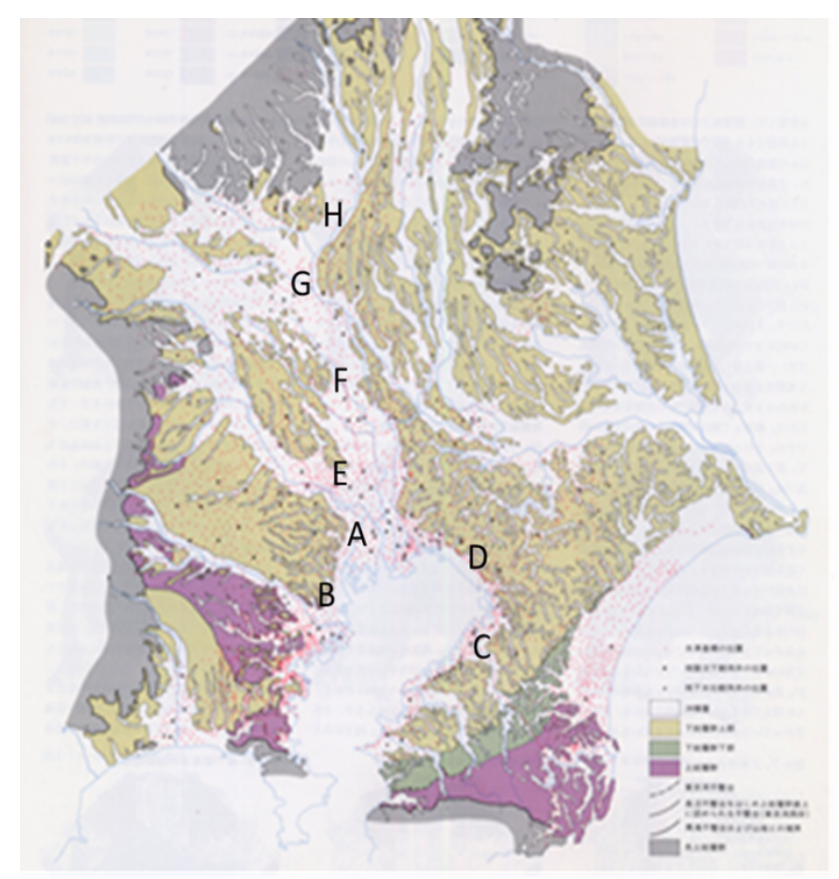

Figure 2. Kanto groundwater basin and the distribution of monitoring wells and benchmarks. Large dots: monitoring wells, small dots: benchmarks. A-E: monitoring wells which data were used in Fig. 3. 
dence. This area covers about half of the Kanto groundwater basin. Consequently, the actual pumping volume is estimated to have been twice as much as the values mentioned above. The groundwater has been used for (1) drinking water supply, (2) industries, (3) agriculture (4) buildings and (5) other uses. The used volume increases generally according as drinking water supply, industries and so on increase in scale. However the used volume shows a little difference based on each autonomy on the Kanto groundwater basin and the scale of the volume used by the agriculture and the building is different at each prefectural government. The volume of other uses is the smallest amount of the volume which is the fifth order. The fact that the drinking water supply make up the largest amount of the ground water use may be the consequence of the concept that necessary of groundwater use is for the benefit of inhabitants (Shibasaki, 1976; Research Group for Water Balance, 1976).

\section{Control of pumping volume and change of ground level and land subsidence}

Groundwater and brine groundwater were pumped up disorderly by companies, farmers and local governments for industry, agriculture, drinking water supply and production of natural gas and iodine before 1960s. However, the regulation by national government began in the middle 1960s and local governments began from the 1970s as progress of the subsidence became remarkable in order to prevent land subsidence.

Each local government has attempted to regulate the pumping volume of the groundwater in order to prevent land subsidence from 1970s. For example, users are required to report the pumping volume compulsorily. Criteria of depth and diameter of discharge pipes were set up (Prefectural Governors' Committee for Land subsidence Prevention in Kanto District, 1983). An agreement to control the pumping of fossil sea water containing natural gas was also made between the Chiba prefecture administration and each gas production company. The condition of groundwater levels in the whole Kanto groundwater basin has recently been clarified. The number of observation wells was 375 in total as of 1982 (Furuno et al., 1983), 459 as of 1991 and about 500 as of 2010s. The amount of land subsidence has been measured by yearly precise leveling. The number of benchmarks attained 4880 and the total length of the leveling, $7363.6 \mathrm{~km}$ as of 1983,4945 benchmarks and $7387.6 \mathrm{~km}$ as of 1986 , about 5000 benchmarks and $7500 \mathrm{~km}$ as of $2010 \mathrm{~s}$, The groundwater management in the shimosa sub-groundwater basin is described as below.

\section{Control of groundwater over-pumping}

In the Keihin industrial zone (coastal zone of Tokyo, Yokohama and Kawasaki) located in the south western part of

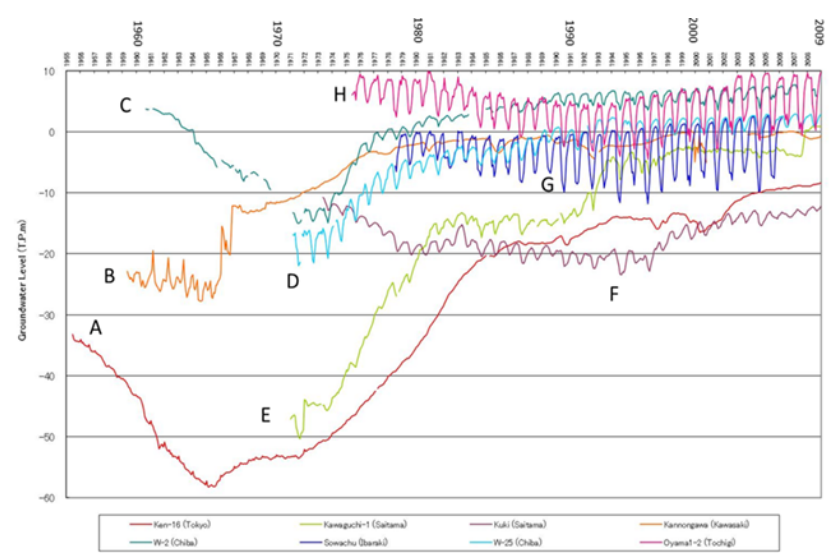

Figure 3. Historical change of the groundwater level in the Kanto groundwater basin. A: Ken-15 (Tokyo), B: Kannongawa (Kawasaki), C: W-2 (Chiba), D: W-25 (Chiba), E: Kawaguchi-1 (Saitama), F: Kuki (Saitama), G: Sowachu (Ibaraki), H: Oyama1-2 (Tochigi).

the Kanto groundwater basin, the land subsidence caused by over-pumping of groundwater were recognized in early 1940s. As a result, industrial aqueducts were established to replace the groundwater pumping from the coastal zone of Kawasaki and Yokohama. In the industrial zone, the pumping was controlled in the 1950s by regulations on the depth of wells and the diameter of discharge pipes. In the industrial zone of Tokyo and its suburbs, the pumping volume was controlled in the 1960s by two laws concerning industrial water and pumping at building sites. However, the countermeasures for land subsidence were often loosely applied by groundwater users, especially the industrial users. In the 1970 s, with the rapid growth of the Japanese economy, land subsidence have been recognized as the most important problems. In such a social background, not only the national government enacted the strict criteria for the regulation concerning the industrial water and the pumping up law for building use, but also the prefectural governments in the southern part of the Kanto groundwater basin strictly applied these regulations. As a result, the groundwater level and the land subsidence stopped gradually. It was even recognized in certain regions that the groundwater level rose. However, excessive regulations produce another problem in some areas. Tokyo Station and Ueno Station in Tokyo set up deep underground platforms before early 1960s when groundwater level was low. Groundwater level rose from late 1960s and buoyancy acted on the building. Those stations had to set up anchors and weights as a countermeasure of buildings rising by buoyancy. Rising of groundwater level in man-made strata and Holocene deposit increase the risk of liquefactionfluidization. We need to keep proper groundwater level. 


\section{Change of groundwater level}

It was in the early 1960s that the groundwater level fell to $60 \mathrm{~m}$ below sea level in the coastal industrial zone of Tokyo metropolis. After that, the recovery of the groundwater level was monitored according to the pumping up control. In the 1970s the regulations were strictly adhered to in the southern Kanto groundwater basin. Accordingly, in the years from 1975 to 1980 , the groundwater level recovered $30-40 \mathrm{~m}$ in the area where groundwater level lowered. Thus the groundwater level showed a recovering tendency in the lowest groundwater level area. The area where groundwater level dropped 20-30 m below sea level has expanded. In other words, a center of groundwater depression moved to the northern part because the pumping control in the southern Kanto groundwater basin is applied strictly. Figure 3 shows historical groundwater change of the monitoring wells and Fig. 4 shows groundwater level of Kanto groundwater basin (Shimosa sub-groundwater) in 2011 based on the monitoring wells. As Fig. 4 shows, groundwater level is not so low as the former 60 but $20 \mathrm{~m}$ below sea level. The lowest groundwater level is stable around $10-20 \mathrm{~m}$ below sea level recently. We should think about the use of appropriate groundwater based on monitoring. Drinking water should have top priority.

\section{Change of land subsidence}

The land surface has been sinking to below sea level in the downtown Tokyo area for mixed industry and residential uses (Shitamachi) since 1910s. Coincidentally, the areas showing ground level lower than mean sea level and high water level of ordinary spring tide of Tokyo Bay were widely scattered. Recently, however, these phenomena have been recognized in alluvial area not only in Shitamachi of Tokyo, but also in suburbs of Tokyo such as Kawasaki and Yokohama in Kanagawa Prefecture, Funabashi, Gyotoku and Urayasu on western Chiba Prefecture. This land subsidence has been stabilized by the regulation of the pumping. The land subsidence was stopped in certain areas and the ground surface slightly uplifted by the recovery of the groundwater level. On the other hand, in the area from central to northern part of the Kanto groundwater basin, land subsidence has begun to sink as a result of over-pumping. That is, land subsidence area is moving northward. Land subsidence before 1970s spread lowland area around Tokyo Bay and Kujyukuri in Boso Peninsula which faced the Pacific Ocean (Fig. 5).

\section{Conclusion}

It is necessary to establish a more effective monitoring system for continuous observation of the groundwater pumping, groundwater level and land subsidence, and to decide the pumping volume in consideration of the change of the groundwater level and the ground movement with the law

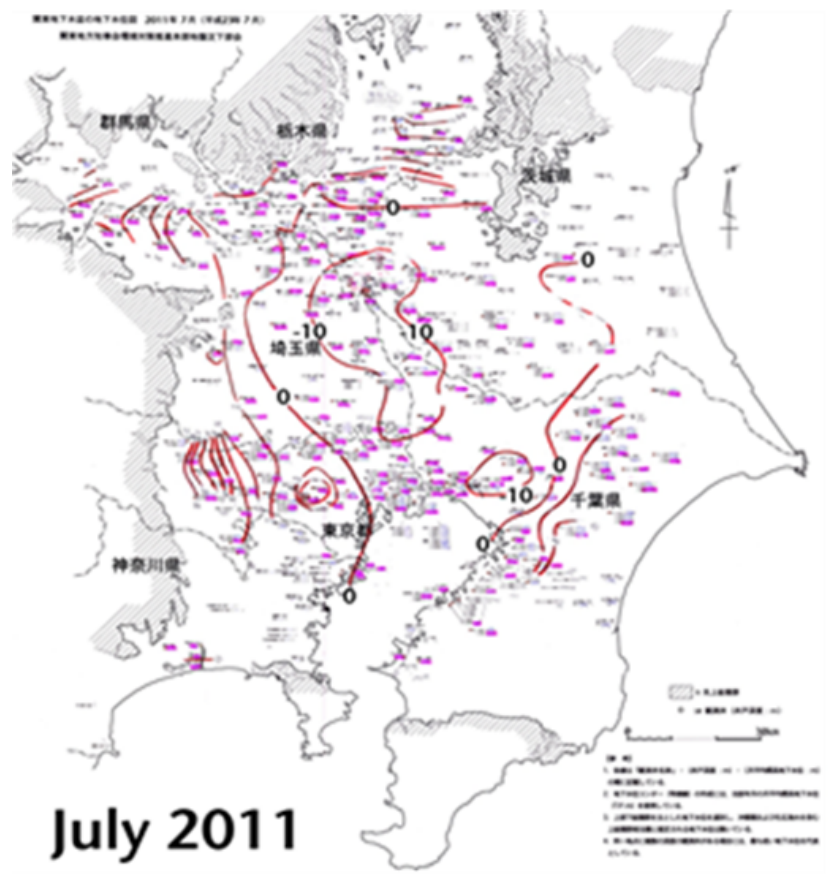

Figure 4. Confined groundwater level in the Kanto groundwater basin (especially the Shiosa sub-groundwater basin). Lowest contour line shows $10 \mathrm{~m}$ below sea level.

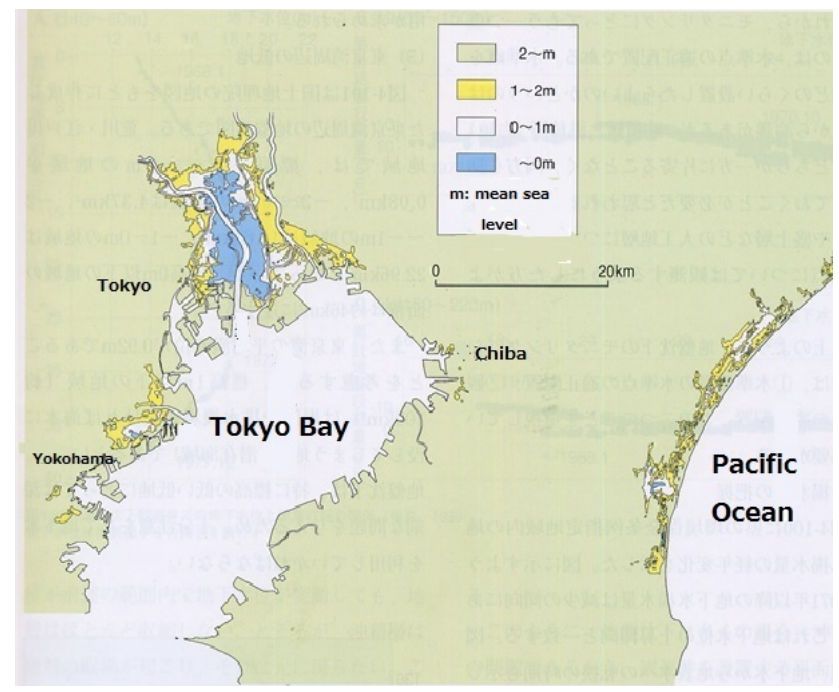

Figure 5. Lowland area around Tokyo Bay and Kujyukuri which faced the Pacific Ocean.

of dynamic equilibrium between man and nature due to the relation among human groups. In other words, the groundwater resources can be used while the health condition of the groundwater basin is examined by periodical health checks. The long-term monitoring of land subsidence and groundwater is important for the sustainable use of the groundwater in the groundwater basin. 
Acknowledgements. We sincerely appreciate members of Research Institute of Environmental Geology, Chiba and members of the local governments of Kanto district who have developed a monitoring system and kept on recording land subsidence and groundwater level.

\section{References}

Aihara, S., Ugata, H., Miyazawa, K., and Tanaka, U.: Problems on groundwater control in Japan, in: Land subsidence, IAHSUNESCO, 2, 635-644, 1969.

Furuno, K., Nemoto, K., Takanashi, Y., Yada, T., Takizawa, H., Oshima, K., Saotome, W., and Nirei, H.: The Monitoring of land subsidence and groundwater head in the Kanto groundwater basin, Bulletin of Chiba Prefectural Research Institute for Environmental Pollution, 15, 99-108, 1983.

Ministry of Environment: Review of land subsidence, available at: http://www.env.go.jp/water/jiban/chinka.html (last access: 20 September 2015), 2015 (in Japanese).

Nirei, H. and Furuno, K.: Development of Quaternary Resources and Environmental Protection: Status of Underground fluid resources use in the Kanto groundwater basin, in: Recent Progress of Quaternary Research in Japan, edited by: Kaizuka, S., Aso, M., Endo, K., et al., National Committee for Quaternary Research in Japan, Tokyo, 11, 71-80, 1986.
Nirei, H., Kusuda, T., Suzuki, K., Kamura, K., Furuno, K., Hara, Y., Satoh, K., and Kazaoka, O.: The 1987 East Off Chiba Prefecture Earthquake and It's Hazards, Memoirs of the Geological Society of Japan, 35, 31-46, 1990.

Prefectural Governors' Committee for land subsidence Prevention Kanto District: Report of groundwater volume pumping up, 228 pp., 1983 (in Japanese).

Prefectural Governors' Committee for land subsidence Prevention Kanto District: Report of groundwater volume pumping up, 124 pp., 2008 (in Japanese).

Research Committee on Land subsidence in Southern Kanto District: Report of research on land subsidence in Southern Kanto District, 297 pp., 1974 (in Japanese).

Research Group for Water Balance: Groundwater basin management, Tokai University Press, Tokyo, 242 pp., 1976 (in Japanese).

Research Institute of Environmental Geology: The Data Analysis on the Urayasu Land Subsidence Observation Well System, Research Institute of Environmental Geology, Chiba, Project Research Report No. 4, 86 pp., 1979. (in Japanese)

Shibasaki, T.: Carrying capacity of groundwater development and conservation, Groundwater basin management, Tokai University Press, Tokyo, 47-75, 1976 (in Japanese). 